\title{
Testing the relationship between the solar radiation dose and surface DMS concentrations using in situ data
}

\author{
C. J. Miles, T. G. Bell, and T. M. Lenton \\ Laboratory for Global Marine and Atmospheric Chemistry (LGMAC), School of Environmental Sciences, University of East \\ Anglia, Norwich, NR4 7TJ, UK
}

Received: 28 January 2009 - Published in Biogeosciences Discuss.: 13 March 2009

Revised: 7 August 2009 - Accepted: 31 August 2009 - Published: 28 September 2009

\begin{abstract}
The proposed strong positive relationship between dimethylsulphide (DMS) concentration and the solar radiation dose (SRD) received into the surface ocean is tested using data from the Atlantic Meridional Transect (AMT) programme. In situ, daily data sampled concurrently with DMS concentrations is used for the component variables of the SRD (mixed layer depth, MLD, surface insolation, $I_{0}$, and a light attenuation coefficient, $k$ ) to calculate

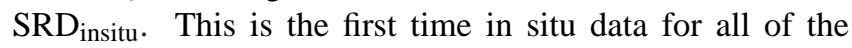
components, including $k$, has been used to test the SRDDMS relationship over large spatial scales. We find a significant correlation $(\rho=0.55 n=65 p<0.01)$ but the slope of this relationship $\left(0.006 \mathrm{nM} / \mathrm{W} \mathrm{m}^{-2}\right)$ is less than previously found at the global $\left(0.019 \mathrm{nM} / \mathrm{W} \mathrm{m^{-2 }}\right)$ and regional scales (Blanes Bay, Mediterranean, $0.028 \mathrm{nM} / \mathrm{W} \mathrm{m}^{-2}$; Sargasso Sea $\left.0.017 \mathrm{nM} / \mathrm{W} \mathrm{m}^{-2}\right)$. The correlation is improved $(\rho=0.74$ $n=65 p<0.01)$ by replacing the in situ data with an estimated $I_{0}$ (which assumes a constant $50 \%$ removal of the top of atmosphere value; $0.5 \times \mathrm{TOA}$ ), a MLD climatology and a fixed value for $k$ following previous work. Equally strong, but non-linear relationships are also found between DMS and both in situ MLD $(\rho=0.61 n=65 p<0.01)$ and the estimated $I_{0}(\rho=0.73 n=65 p<0.01)$ alone. Using a satellite-retrieved, cloud-adjusted surface UVA irradiance to calculate a UV radiation dose (UVRD) with a climatological MLD also provides an equivalent correlation $(\rho=0.67 n=54 p<0.01)$ to DMS. With this data, MLD appears the dominant control upon DMS concentrations and remains a useful shorthand to prediction without fully resolving the biological processes involved. However, the implied relationship between the incident solar/ultraviolet radiation (modulated by MLD), and sea surface DMS concentrations, is critical for closing a climate feedback loop.
\end{abstract}

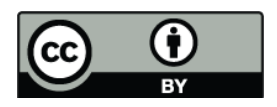

Correspondence to: C. J. Miles (c.miles@uea.ac.uk)

\section{Introduction}

Dimethylsulphide (DMS) is a climatically important biogenic sulphur compound present in surface ocean waters at sufficient concentrations to sustain a significant flux to the remote marine atmosphere (Bates et al., 1992). There, sulphate aerosols derived from the oxidation of DMS are a major source of cloud condensation nuclei $(\mathrm{CCN})$, promoting cloud formation and increasing cloud albedo (Andreae and Crutzen, 1997; Ayers et al., 1991; Ayers and Gillett, 2000; Berresheim et al., 1993; Sciare et al., 2001). The resulting impact at the surface is expected to be a reduction in solar insolation and a net cooling. The CLAW hypothesis proposes a feedback loop whereby phytoplankton producing DMS alter their environment by modulating incoming solar radiation, engendering a change in surface ocean conditions whilst simultaneously increasing cloud albedo, with global climatic consequences (Charlson et al., 1987). A prerequisite for the closure of any feedback loop is that environmental variables affected by cloud albedo (e.g. insolation, temperature) can in turn influence seawater DMS concentrations. However, the controls on seawater DMS concentrations, hereafter [DMS], and its associated biological processes are complex and are yet to be fully resolved (Simó, 2001).

Various biogeochemical and physical parameters have been proposed as controls on seawater [DMS] and attempts have been made to incorporate some of the most rigorous into explanatory/predictive algorithms. These include an algorithm using chlorophyll concentration, light and a nutrient term based upon Michaelis-Menton kinetics (Anderson et al., 2001) and algorithms based upon plankton community composition indexes calculated from accessory pigment concentrations (Aumont et al., 2002; Belviso et al., 2004b). A proposed relationship between mixed layer depth (MLD) and [DMS] (Simó and Pedros-Alio, 1999) was adapted and extrapolated to produce global DMS fields derived from MLD and chlorophyll- $a$ concentration (Simó and Dachs, 2002).

Published by Copernicus Publications on behalf of the European Geosciences Union. 
Aranami and Tsunogai (2004) investigated the MLD-based relationship using regional data and suggested that much of the variance in DMS concentrations could be explained by a simpler relationship with MLD alone based on a dilution effect. Belviso et al. (2004a) compared the five aforementioned algorithms utilising a global database of surface seawater [DMS] (http://saga.pmel.noaa.gov/dms/) and found that different algorithms are more skilful predictors of DMS concentrations in different regions. Bell et al. (2006) analysed data collected as part of the Atlantic Meridional Transect (AMT) programme to test these predictive algorithms and found that a refined version of the Aranami and Tsunogai (2004) algorithm ([DMS] $\alpha 40 /$ MLD) was the best fit for the data.

Vallina and Simó (2007) have demonstrated a strong positive relationship between sea surface [DMS] and the solar radiation dose (SRD) received into the upper mixed layer of the ocean. This is identified at two fixed locations and at the global level utilising monthly averaged data. A further strong positive relationship has been reported between the SRD, atmospheric DMS oxidation and satellite derived CCN over large areas of the global ocean (Vallina et al., 2007). The global SRD methodology combines a climatological mixed layer depth (MLD), the estimated solar radiation incident at the surface $\left(I_{o}\right)$ derived from a top of atmosphere value $(0.5 \times \mathrm{TOA})$ and the attenuation of total solar radiation within the water column $(k)$ represented by a constant fixed value $\left(0.06 \mathrm{~m}^{-1}\right)$. The SRD is essentially a measure of the average light level experienced by the cells confined within the mixed layer in $\mathrm{Wm}^{-2}$. This positive relationship potentially closes a negative feedback loop between incident solar radiation and marine emissions of DMS, sulphate aerosols, $\mathrm{CCN}$, cloud albedo and climate as postulated by the CLAW hypothesis.

Central to the relationship between the SRD and seawater [DMS] is the proposed interaction between incident surface radiation and MLD. The depth of the mixed layer is expected to have a substantial influence on [DMS] (Simó and Pedros-Alio, 1999). Stratified waters, although sustaining a lower overall phytoplankton biomass, are characterised by a species assemblage composed of more prolific dimethylsulphoniopropionate (DMSP) producers (Simó and PedrosAlio, 1999). DMSP is the dominant biological precursor to DMS as DMSP cleavage by lyase enzymes is a significant DMS production pathway (Steinke et al., 1998, 2002). In addition, a shallow mixed layer results in elevated exposure to UV irradiance, which inhibits heterotrophic bacterioplankton production as a result of DNA damage caused by UV-B radiation (Slezak et al., 2001; Toole et al., 2006). Reduced bacterioplankton production leads to reduced DMS consumption rates (Toole et al., 2006). The combination of these factors has been shown to increase [DMS] when surface waters are highly stratified (Simó and Pedros-Alio, 1999).

Laboratory studies of the diatom Thalassiosira pseudonana and the prymnesiophyte Emiliania huxleyi have shown that elevated DMS production occurs in response to high
UV irradiance with the largest effect under exposure to UVA wavelengths (320-400 nm) (Sunda et al., 2002). Oxidative stressors (including UV) generate harmful free radicals in the cell, while DMSP, DMS and subsequent DMS oxidation products have been shown to readily scavenge hydroxyl radicals and other reactive oxygen species, relieving oxidative stress (Sunda et al., 2002).This suggests an antioxidant function for the DMS(P) cycle, linking it with UV-induced oxidative stress in marine phytoplankton (Sunda et al., 2002). DMS can also be removed from the water column by photo-oxidation to dimethyl sulfoxide (DMSO) following exposure to UV-B radiation (Brimblecombe and Shooter, 1986), whilst (Kniveton et al., 2003) have demonstrated that extreme changes in UV can cause a reduction in atmospheric DMS on a daily timescale, most likely attributable to photodestruction in the atmosphere. Thus the same shallow MLD and high insolation levels and durations associated with peak summer [DMS] are seemingly ideal for high photochemical loss rates. The photo-oxidation of DMS does not typically dominate as a loss term because it is dependent upon the presence of chromophoric dissolved organic matter (CDOM) which is at lowest concentrations in the summer (Siegel and Michaels, 1996). Summer is when the MLD is shallowest and UV irradiance levels are highest and these factors combined (SRD) may help explain the DMS "summer paradox" whereby peak [DMS] occur in the summer despite phytoplankton production, biomass and chlorophyll levels reaching maxima earlier in the year (Toole et al., 2003).

Considering the current state of knowledge, we decided to test the reported relationship between SRD and seawater [DMS] (Vallina and Simó, 2007). Belviso and Caniaux (2009) also tested the strength of the SRD-DMS relationship in the North-East Atlantic (using data from the Programme Ocean Multidisciplinaire Meso-Echelle (POMME) experiment). From their data, they conclude that SRD and DMS do not demonstrate a strong correlation (with SRD accounting for only $19 \%-24 \%$ of the variance associated with monthly surface DMS concentrations). However, their [DMS] data is not normally distributed and the result from their Spearman's Rank correlation analysis may be more appropriate, suggesting a stronger correlation of $\rho=0.74$. The authors then conducted a sensitivity analysis using different versions of the SRD equation and suggest that the DMS-SRD relationship is heavily influenced by the choice of fixed irradiance attenuation coefficient $(k)$.

In contrast to the global SRD relationship of Vallina and Simó (2007) and the work of Belviso and Caniaux (2009), our study uses in situ, daily data from the AMT project sampled concurrently with DMS concentrations for all component variables of the SRD (MLD, $I_{0}$ and $k$ ) to calcu-

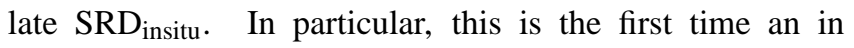
situ and thus variable $k$ has been used to test the SRD calculation over such a large spatial scale. The AMT [DMS] data is also compared to a SRD calculated using 
climatological/estimated inputs $\left(\mathrm{SRD}_{\text {clim }}\right)$ using the same methodology and data sources as the global study of Vallina and Simó (2007). The regional studies of Vallina and Simó (2007) and Belviso and Caniaux (2009) are from the coastal northwest Mediterranean (Blanes Bay $41^{\circ} 3 \mathrm{~N}$, $\left.2^{\circ} 48 \mathrm{E}\right)$, Sargasso Sea $\left(32^{\circ} 10 \mathrm{~N}, 64^{\circ} 30 \mathrm{~W}\right)$ and northeast Atlantic $\left(16^{\circ} \mathrm{W}-22^{\circ} \mathrm{W}, 38^{\circ} \mathrm{N}-45^{\circ} \mathrm{N}\right)$ respectively. Analysing in situ data from different locations is vital to advance understanding of the reported global relationship that has been demonstrated with in situ data in these regions. The equatorial/oligotrophic regions covered by our analysis are especially critical as it is here that the decoupling of [DMS] from measures of biomass/chlorophyll (summer paradox) are observed.

Our results broadly support those presented previously (Vallina and Simó, 2007; Belviso and Caniaux, 2009), but also elaborate upon the importance of $k$ and MLD in the SRD equation. We also attempt to directly address UV radiation, adapting the SRD methodology to calculate an ultraviolet radiation dose (UVRD) that restricts the total surface irradiance to a narrower spectral band relevant to UVA $(380 \mathrm{~nm})$. Finally, a comparison is made to the work of Bell et al. (2006) who previously found the best fit to the AMT DMS data to be a simple relationship with MLD alone (40/MLD) (see Methods Sect. 2 for details).

\section{Methods}

The SRD combines the depth of the mixed layer (MLD), the incident solar radiation at the surface $\left(I_{0}\right)$ and its attenuation within the water column $(k)$ (Vallina and Simó, 2007):

$\mathrm{SRD}=\frac{I_{0}}{k \cdot \mathrm{MLD}} \cdot\left(1-e^{-k \cdot \mathrm{MLD}}\right)$

Throughout their global study, Vallina and Simó (2007) use a fixed value of $k$ representative of the attenuation of total solar radiation by clear ocean water $\left(0.06 \mathrm{~m}^{-1}\right)$ and estimate $I_{0}$ on the assumption that a constant $50 \%$ of the solar radiation incident at the top of the atmosphere reaches the surface $(0.5 \times \mathrm{TOA})$. MLD is taken from a $2^{\circ} \times 2^{\circ}$ resolution global climatology (de Boyer Montégut et al., 2004). The mixed layer is characterised by almost vertically uniform salinity, temperature, and density profiles. The MLD is defined as the point at which a departure from this uniform state can be detected based upon an arbitrary choice of criteria such as temperature, salinity or density (de Boyer Montégut et al., 2004). The criterion used to define the climatological MLD is a temperature change of $0.1^{\circ} \mathrm{C}$ from a near surface value of $5 \mathrm{~m}$ (as used by Vallina and Simó, 2007).

In this study we use daily in situ data for the components of the SRD equation $\left(I_{0}\right.$, MLD, $\left.k\right)$ and surface [DMS] sampled concurrently during the AMT programme. The AMT program undertakes research cruises between the UK and the Falkland Islands transecting a range of ecosystems but focusing upon the oligotrophic mid-ocean gyres of the North and
South Atlantic. This study uses data collected during northern hemisphere spring (cruises AMT-12 in May-June 2003; and AMT-14 in April-June 2004) and autumn (AMT-13 in September-October 2003) (Fig. 1.) (see Bell et al., 2006, for more detail). To calculate $\mathrm{SRD}_{\text {insitu }}$ it is necessary to not only have a [DMS] measurement at a sampling point but also concurrent data for the components of the SRD (MLD, $I_{0}$ and $k$ ). Within the AMT dataset, this meant that only 65 DMS data points could be used with concurrent data. Although it would be possible to calculate SRD using climatological data $\left(\mathrm{SRD}_{\text {clim }}\right)$ for more of AMT data points, the analysis was restricted to the same dataset to enable a fair comparison. The same reasoning was applied to the UVRD analysis which used all available UV data in conjunction with the DMS data used for the SRD analysis.

For incident solar radiation $\left(I_{0}\right)$, a daily average $(24 \mathrm{~h}$ leading up to the point of sampling) of the continuous shipboard measurements of total solar radiation was used. Measurements in $\mathrm{Wm}^{-2}$ were made using Kipp \& Zonen SP Lite 0339-900 TIR Pyranometers (range 300-3000 nm) that were positioned high up on the ship's foremast approximately $22 \mathrm{~m}$ a.s.l. The average of two sensors was used and the same instrumentation used on all cruises. The in situ MLD is defined using the same criteria as the V\&S07 MLD climatology, a temperature departure of $0.1^{\circ} \mathrm{C}$ from a reference depth of $5 \mathrm{~m}$ to avoid the effect of diurnal heating (Bell et al., 2006). The temperature profiles used to calculate the MLD were sampled concurrently with [DMS] along the cruise track at pre-dawn (03:00 LT) each day. The attenuation coefficient $(k)$ used for the $\mathrm{SRD}_{\text {insitu }}$ was calculated using the sampled $1 \%$ light level depth $\left(Z_{e}\right)$ defined as the depth (m) to which $1 \%$ of the light incident at the surface penetrated on the previous day's mid-morning (11:00 LT) cast $\left(k=\ln (0.01) / Z_{e}\right)$.

We also calculated an ultraviolet radiation dose (UVRD, Eq. 2) based on the SRD equation (Eq. 1) but using a satellite surface UV product from NASA's Total Ozone Mapping Spectrometer (TOMS) in place of in situ total solar irradiance $\left(I_{o}\right)$. This was in the form of the noon irradiance for the specific DMS sampling date at the surface of the ocean in $\mathrm{mW} \mathrm{m}{ }^{-2} \mathrm{~nm}^{-1}$ at $380 \mathrm{~nm}(\mathrm{UVA})$ and at a $1^{\circ} \times 1^{\circ}$ degree grid box resolution. This product incorporates the column ozone amount and cloud conditions, taking into account sun-earth distance, solar zenith angle, total ozone amount, tropospheric aerosol optical depth and cloud transmission (Herman and Celarier, 1997) and is available from the TOMS project at http://toms.gsfc.nasa.gov/. This product does not account for daylength and as such it should be noted that the methodology differs from the SRD which uses a daily average value. A constant attenuation coefficient appropriate for the attenuation of UV under oligotrophic conditions $\left(k=0.10 \mathrm{~m}^{-1}\right)$ was applied (Tedetti and Sempere, 2006) as no appropriate in situ measurements were available.

$\mathrm{UVRD}=\frac{\mathrm{UV}_{380 \mathrm{~nm}}}{k \cdot \mathrm{MLD}} \cdot\left(1-e^{-k \cdot \mathrm{MLD}}\right)$ 


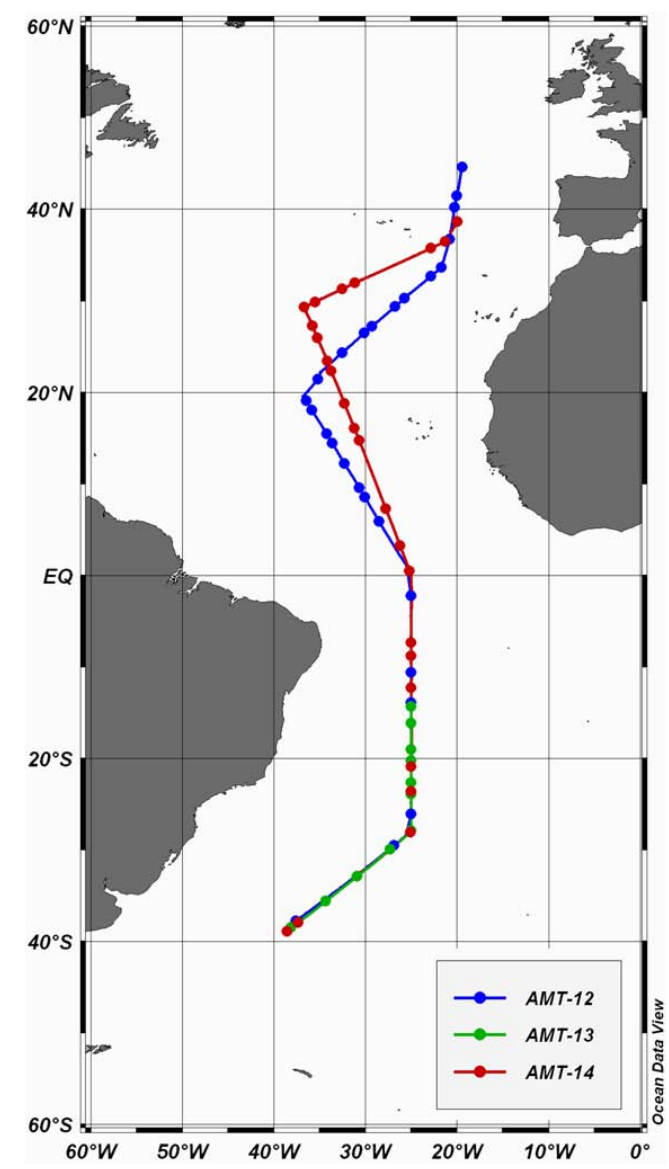

Fig. 1. Location of the AMT cruise tracks (lines) and sampling stations (markers) from which data was available to calculate the SRD (AMT-12, blue; AMT-13, green; AMT-14, red). Plot produced using Ocean Data View (http://odv.awi.de/en/home/).

These results are also compared to a simpler relationship between MLD and [DMS] (Eq. 3) previously found to be the best fit to this data by Bell et al. (2006)

$\mathrm{DMS} \alpha \frac{40}{\mathrm{MLD}}$

\section{Results}

\subsection{SRD}

When utilising the SRD methodology in conjunction with the in situ AMT data for all of the SRD variables $\left(k, I_{0}\right.$, MLD) ( $\left.S R D_{\text {insitu }}\right)$ we find a strong and significant correlation ( $\rho=0.55 n=65 p<0.01)$ between SRD and [DMS]. The slope of this relationship $\left(0.006 \mathrm{nM} / \mathrm{W} \mathrm{m}^{-2}\right)$ is less than that found by Vallina and Simó (2007) at the global $\left(0.019 \mathrm{nM} / \mathrm{W} \mathrm{m}^{-2}\right)$ and regional levels (Blanes Bay $0.028 \mathrm{nM} / \mathrm{W} \mathrm{m}^{-2}$; Sargasso Sea $0.017 \mathrm{nM} / \mathrm{W} \mathrm{m}^{-2}$ ). As these relationships use monthly averaged values, they are intended to be appropriate for the longer term climatological mean situation (Fig. 2). Vallina and Simó (2007) demonstrate that the SRD is connected to the seasonal DMS cycle at the global level $\left(10^{\circ} \times 20^{\circ}\right.$ grid boxes, $\rho=0.47 n=545 p<0.01)$ and at two fixed locations using monthly averaged data (Blanes Bay $\rho=0.75 n=15$ $p<0.01$; Sargasso Sea: $\rho=0.89 n=33 p<0.01$ ). In contrast the AMT data exhibits significant spatial coverage but represents less seasonal variation, covering only a few months of the seasonal cycle (in Northern Hemisphere spring and autumn). As such, a complete comparison between the two data sets is not possible. However, it is interesting that a strong and significant correlation still exists between SRD and [DMS] when addressing variability on a shorter (daily) timescale in this in situ data series.

The correlation fit to the AMT [DMS] is improved ( $\rho=0.74 n=65 p<0.01)$ when the in situ data is replaced with climatological inputs to the $\mathrm{SRD}$ calculation $\left(\mathrm{SRD}_{\text {clim }}\right)$ following the methodology used in the global analysis of Vallina and Simó (2007). The slope of this relationship $\left(0.010 \mathrm{nM} / \mathrm{W} \mathrm{m}^{-2}\right)$ is also closer to the global relationship reported by Vallina and Simó (2007) (Fig. 2). An initial motivation of this research was to attempt to improve upon the handling by Vallina and Simó (2007) of these climatological variables, $I_{0}(0.5 \times \mathrm{TOA})$, MLD (climatology) and $k$ (fixed). A comparison of the AMT in situ data with climatological data does yield statistically significant correlations. The climatological and in situ MLD compare reasonably well ( $\rho=0.55, n=65, p<0.01)$ although the climatological MLD significantly underestimates the range of MLD and exhibits a shallow bias when compared with the observed, in situ MLD data from AMT (in situ: range 7-144 m, mean $38 \mathrm{~m}$; climatology: range 6-56 m, mean $20 \mathrm{~m}$ ). The in situ and climatological $I_{0}$ values compare more favourably $(\rho=0.78$, $n=65, p<0.01)$. The climatological $I_{0}$ also underestimates the range of solar radiation incident at the surface when compared to the in situ data (in situ: range $78.2-323.4 \mathrm{Wm}^{-2}$, mean $226.1 \mathrm{Wm}^{-2}$; climatology: range $=98.9-241.9 \mathrm{Wm}^{-2}$, mean $210.1 \mathrm{Wm}^{-2}$ ). This underestimated range can be explained because the estimated $I_{0}$ uses a $0.5 \times$ TOA value that does not account for varying cloud cover. In this shorter, high resolution dataset, variable cloud cover is expected to play an important role especially given the AMT cruise track crossing the equator and the inter-tropical convergence zone (ITCZ). The fixed value of $k\left(0.06 \mathrm{~m}^{-1}\right)$ utilised by Vallina and Simó (2007) falls within the range of in situ $\mathrm{k}$ values from the AMT dataset $\left(0.03-0.11 \mathrm{~m}^{-1}\right.$, mean $\left.=0.05 \mathrm{~m}^{-1}\right)$.

Similar strength correlations to that observed between [DMS] and SRD are also observed between [DMS] and MLD (in situ MLD: $\rho=0.61 n=65 p<0.01$, climatological MLD: $\rho=0.70 n=65 p<0.01)$ and climatological $I_{0}(\rho=0.74$ $n=65 p<0.01$ ). To investigate the SRD further we examined the components of the equation to try and determine their respective influences upon the observed correlations between the SRD and [DMS] (Table 1).

Replacing the in situ, variable light attenuation coefficient $(k)$ within the SRD equation with a fixed value $\left(0.06 \mathrm{~m}^{-1}\right)$ 

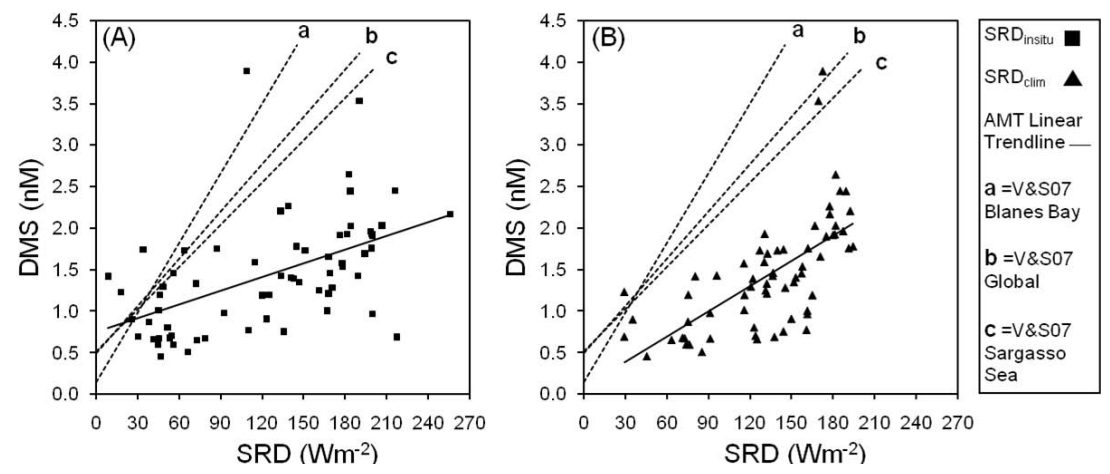

Fig. 2. $[\mathrm{DMS}](\mathrm{nM})$ versus $\mathrm{SRD}\left(\mathrm{W} \mathrm{m}^{-2}\right)$ calculated using: (a) in situ data $\left(\mathrm{SRD}_{\mathrm{insitu}}\right.$, squares); and (b) climatological data $\left(\mathrm{SRD}_{\mathrm{clim}}\right.$, triangles), for MLD, $k$ and $I_{0}$. On both plots, solid line is linear best fit regression of the data, (a) SRD insitu $_{\text {DMS }}$ D.755+0.006.SRD, (b) $\mathrm{SRD}_{\text {clim }}$ : $\mathrm{DMS}=0.084+0.010 . \mathrm{SRD}$ ). Dashed lines a-c are the relationships between [DMS] and SRD reported by Vallina and Simó (2007) (a=V\&S07 Blanes Bay, DMS=0.138+0.028.SRD; b=V\&S07 Global, DMS=0.492+0.019.SRD; c=V\&S07 Sargasso Sea, $\mathrm{DMS}=0.51+0.017 . \mathrm{SRD})$.

uniformly increases the correlation with [DMS] (Table 1). This could partly explain the difference in the correlation to [DMS] between $\mathrm{SRD}_{\text {insitu }}$ and $\mathrm{SRD}_{\text {clim. The correlation to }}$ [DMS] is almost always increased when the in situ $I_{0}$ is replaced with the estimated $I_{0}(0.5 \times \mathrm{TOA})$. Fixing the MLD significantly decreases the correlation in conjunction with in situ $I_{0}$ but a fixed MLD in combination with an estimated $I_{0}$ $(0.5 \times$ TOA) returns a high correlation (Table 1$)$. The SRD permutations offer some improvement upon the simpler relationships between [DMS] and MLD (40/MLD) (MLD climatological: $\rho=0.70 n=65 p<0.01$, MLD in situ: $\rho=0.61 n=65$ $p<0.01$ ). Using an $I_{0}$ derived from a TOA value that does not account for cloud $(\rho=0.73 n=65 p<0.01)$ also performs as well as using the optimum $\mathrm{SRD}$ formulation $\left(\mathrm{SRD}_{\text {clim }}\right)$.

\subsection{UVRD}

Results from the literature (Toole and Siegel, 2004; Toole et al., 2006; Sunda et al., 2002) led us to investigate the SRD equation from the perspective of surface UV irradiance (UVRD, Eq. 3), utilising a cloud-adjusted satelliteretrieved surface UVA irradiance (no direct measurements of UV were available from the AMT) within the SRD methodology (see Methods for details). A fixed value for $k$ was adopted as no direct measurements were available from the AMT with an appropriate value for these oligotrophic conditions $\left(k=0.10 \mathrm{~m}^{-1}\right)$ selected from the literature (Tedetti and Sempere, 2006). The best results were achieved when using UVA $(380 \mathrm{~nm})$ in this study and this is consistent with previous work. Toole and Siegel (2004) attribute observed patterns of DMS cycling in the oligotrophic Sargasso Sea to a stress forced mechanism associated with UVA irradiance, while Sunda et al. (2002) noted elevated [DMS] with exposure to UVA wavelengths under laboratory conditions.

The UVRD calculated using a climatological MLD is well correlated to [DMS] from AMT $(\rho=0.67 n=54 p<0.01)$ (Fig. 3) and is a better fit to the [DMS] data than the
Table 1. Spearman's rank correlation coefficients $(\rho)$ between [DMS] and the outcome of the 3 equations on test (SRD, Eq. 1; UVRD, Eq. 2; 40/MLD, Eq. 3) with various combinations of the available climatological/in situ data as input variables $\left(I_{0} / \mathrm{UV}_{380 \mathrm{~nm}}\right.$, MLD and $\left.k\right)$. Bold coefficients indicate that an appropriate fixed value of $k$ is used $\left(0.06 \mathrm{~m}^{-1}\right.$ for $I_{0}, 0.10 \mathrm{~m}^{-1}$ for UVA) (see methods for further details). Plain text indicates that the in situ value for $k$ is used. The simpler DMS $\alpha 40 /$ MLD coefficients (italics) does not utilise a $\mathrm{k}$ value. All coefficients significant at $p<0.01$ unless marked with * (in which case, result is not significant at $p<0.05$ ). For correlations involving UVA $n=54$, otherwise $n=65)$.

\begin{tabular}{llllll}
\hline & $\begin{array}{l}I_{0} \\
\text { In situ }\end{array}$ & $\begin{array}{l}I_{0} \\
\text { Clima- } \\
\text { tology }\end{array}$ & $\begin{array}{l}I_{0} \\
\text { Fixed }\end{array}$ & $\begin{array}{l}\text { UVA } \\
\text { (satellite) }\end{array}$ & 40/MLD \\
\hline MLD In situ & 0.55 & 0.55 & 0.48 & n/a & \\
& $\mathbf{0 . 6 2}$ & $\mathbf{0 . 6 1}$ & $\mathbf{0 . 6 1}$ & $\mathbf{0 . 5 5}$ & 0.61 \\
MLD Climatology & 0.53 & 0.58 & 0.42 & n/a & 0.70 \\
& $\mathbf{0 . 6 2}$ & $\mathbf{0 . 7 4}$ & $\mathbf{0 . 7 1}$ & $\mathbf{0 . 6 7}$ & \\
MLD Fixed & 0.46 & 0.71 & n/a & n/a & n/a \\
& $\mathbf{0 . 4 7}$ & $\mathbf{0 . 7 3}$ & n/a & $\mathbf{0 . 2 6 *}$ & \\
\hline
\end{tabular}

$\operatorname{SRD}_{\text {insitu }}$ with either variable, in situ $k$ values $(\rho=0.56 n=66$ $p<0.01)$ or fixed $k$ values $(\rho=0.63 n=66 p<0.01)$. However, the UVRD does not improve upon the correlation between [DMS] and the $\operatorname{SRD}_{\text {clim }}(\rho=0.74 n=66 p<0.01)$ although it does use a more appropriate surface irradiance (i.e. cloud adjusted) component. Once again the correlation between UVRD and [DMS] is very similar to the strength of the correlations found between the simpler relationships with [DMS] and MLD alone (40/MLD) or the estimated $I_{0}$ derived from the TOA value $(0.5 \times \mathrm{TOA})$.

\section{Discussion}

The SRD calculated using in situ components from the AMT $\left(\mathrm{SRD}_{\text {insitu}}\right)$ produces a statistically significant correlation to 


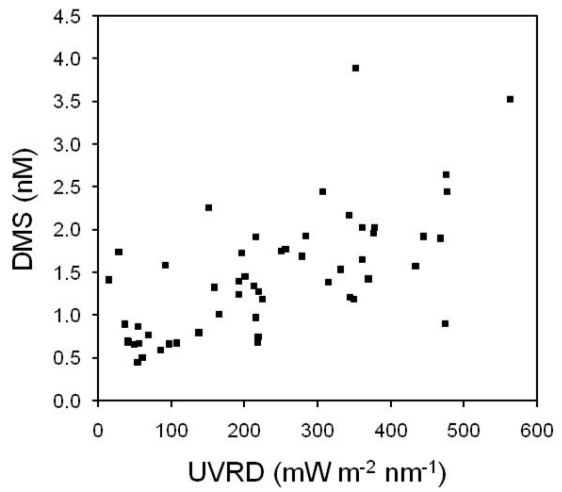

Fig. 3. $[\mathrm{DMS}](\mathrm{nM})$ versus $\mathrm{UV}$ radiation dose (UVRD, $\mathrm{mW} \mathrm{m} \mathrm{nm}^{-1}$ ) calculated using a climatological MLD, a constant $k\left(0.10 \mathrm{~m}^{-1}\right)$ and satellite-derived UVA $(380 \mathrm{~nm})$ at the surface ( $\rho=0.67 n=54 p<0.01)$ (see methods for further details).

the concurrently sampled, high resolution [DMS] data. This application is beyond the remit originally proposed. The strength of this correlation is reduced relative to the global and fixed location studies of Vallina and Simó (2007) and the slope of the relationship between SRD and DMS is less. Notably, the correlation fit is improved when in situ data is replaced with estimated/climatological values as inputs to the SRD $\left(\mathrm{SRD}_{\text {clim }}\right)$, the same approach used to derive the global SRD relationship of Vallina and Simó (2007). This also brings the slope into better agreement with the slopes identified by Vallina and Simó (2007), although variability in slope can be expected given the varying temporal and spatial nature of the cruise track sampling points and the resolution/time period of the data. These results are in agreement with the strength of Spearman's Rank correlation $(\rho=0.74$ $n=232 p<0.01$ ) reported between the SRD and [DMS] from the North East Atlantic over a seasonal cycle by Belviso and Caniaux (2009).

A change from a variable, in situ light attenuation coefficient $(k)$ to a fixed value significantly increased the strength of correlation with [DMS] across the range of SRD equation permutations. Fixing $k$ effectively removes it from the equation in terms of a correlation fit to the data. As Belviso and Caniaux (2009) demonstrate, the value of $k$ can have a substantial impact on the value of SRD. Our data suggests that allowing $k$ to vary significantly reduces the strength of correlation between SRD and [DMS] and implies that the inclusion of a variable $k$ within the SRD equation reduces its effectiveness at predicting surface [DMS]. This was the likely cause of much of the difference between $\mathrm{SRD}_{\text {insitu }}$ and $\mathrm{SRD}_{\text {clim }}$ and their strength of correlation with [DMS]. The switch from an in situ $I_{0}$ to an $I_{0}$ derived from a top of the atmosphere value $(0.5 \times \mathrm{TOA})$ appears to account for the remainder of the difference in the strength of correlation of [DMS] with $\mathrm{SRD}_{\text {insitu }}$ and $\mathrm{SRD}_{\text {clim. Similar strength cor- }}$ relations with [DMS] were also found for climatological $I_{0}$ and climatological MLD (40/MLD).
It is important to remember that MLD and $I_{0}$ are not completely independent variables and that the two are likely to be coupled over the seasonal cycle with high insolation levels in the summer coinciding with shallow mixed layers (de Boyer Montégut et al., 2004). The advantage of the SRD methodology is that it combines these two interrelated variables, incorporating a physical mechanism to explain why the seasonal coherence of shallow MLD and high insolation combine to produce high DMS concentrations. The problem is that it becomes difficult to isolate the causal effect of insolation beyond a relationship with MLD driven by seasonality in $I_{0}$ (i.e. the effect of variable $I_{0}$ or SRD given a constant MLD). This is especially apparent when using a non-cloud adjusted, estimated $I_{0}$ in place of in situ $I_{0}$ data.

The main difference between the two measures of surface irradiance is that the in situ $I_{0}$ represents the variability introduced by cloud cover whereas the TOA derived, estimated $I_{0}$ does not (beyond the assumption that 50\% of TOA irradiance is removed). The in situ, daily average $I_{0}$ values must represent more faithfully the surface irradiance that is concurrent with the daily sampled [DMS] but the TOA derived $I_{0}$ is more successful at providing a correlation fit both in combination with the SRD method and when used in isolation. The estimated, TOA-derived $I_{0}$ may be representing the longer-term mean state of the system rather than the snapshot of variability provided by the in situ AMT cruise transect data. Within this high resolution in situ dataset MLD and $I_{0}$ are less likely to be directly coupled and this could explain why the climatological/estimated data is more successful at resolving the observed DMS concentrations. The estimated $I_{0}$ could also represent seasonality in an unknown variable or combination of variables that combine with shallow summer MLD to produce high [DMS]. Finally, it could represent a smoothed (inverse) version of MLD itself with [DMS] modulated by a dilution effect independent of high resolution changes in insolation. In conjunction with smoothed monthly data the inclusion of an estimated $I_{0}$ within the SRD equation may act as a proxy for the seasonality inherent within the DMS cycle, combining latitude and date (seasonality) within one variable. The estimated $I_{0}$ could then represent the background potential for exposure to incident surface radiation whilst variations in MLD control the dose.

A motivation of this work was to attempt to improve upon the handling of the climatological/estimated SRD parameters. A dominant role for MLD within the SRD could explain why using in situ values for $I_{0}$ and $k$ did not yield any improvement in the skill of the SRD equation when applied to this daily data. The combination of a less variable, TOA-derived $I_{0}$ and fixed $k$ would also increase the methodological importance of MLD within the SRD calculation. It should be remembered that although MLD seems to be a key variable within the SRD equation (at least in terms of the AMT data) explicit within the SRD reasoning is the implication that shallow MLD allow insolation/surface processes to influence the dynamics of the DMS(P) food web 
(Simó and Pedros-Alio, 1999). This is hinted at in the relationship between [DMS] and UV found in this study.

Prior to the Great Oxidation 2.4 billion years ago, life on Earth evolved without the protection of a stratospheric ozone layer and under much higher UV levels than today (GarciaPichel, 1998). This evolutionary history may still be reflected in efficient strategies and physiological mechanisms in modern organisms and ecosystems to prevent UV-induced damage and reduce photo-oxidative stress (Häder et al., 2003). This may be relevant in the context of DMS(P) production by marine phytoplankton (Sunda et al., 2002). Addressing UVA directly via the substitution of a cloud adjusted satellite retrieval of surface UVA irradiance (UVRD) did not significantly improve or worsen the correlation to [DMS] relative to the $\mathrm{SRD}_{\text {clim }}$, estimated $I_{0}$ or $40 / \mathrm{MLD}$ relationship. The UVRD equation did improve upon the correlation between [DMS] and SRD $_{\text {insitu }}$ but most importantly yields a strong significant correlation in conjunction with a cloud adjusted measure of surface irradiance in a wavelength previously linked to DMS dynamics. This supports the results of Toole and Siegel (2004), who identified a significant correlation between [DMS] and in situ UV within the mixed layer at a fixed location (Hydrostation S) in the Sargasso Sea over the seasonal cycle. It is important to note that as with SRD the strength of correlation between [DMS] and UVRD was likely to be influenced by fixing the value of $k$. In the future, utilising direct in situ measurements of UVA and UVB coupled with their attenuation $(k)$ within the water column should improve our understanding of UVRD and DMS dynamics.

Within the AMT data, there is little difference between the most highly correlated variation of the SRD equation $\left(\mathrm{SRD}_{\text {clim }}\right)$, the UVRD and the simpler relationships based on in situ MLD (40/MLD) or estimated $I_{0}$ alone. The notion that MLD could be important in modulating DMS concentrations was introduced by Simó and Pedros-Alio (1999) who commented that it was useful shorthand to prediction until the mechanisms controlling DMS concentrations could be resolved. It is questionable from this AMT data whether the inclusion of the variables $I_{0} / \mathrm{UV}$ and $k$ via the SRD methodology improves the correlation enough to illuminate causation over this resolution. Recent work by Derevianko et al. (2009), uses the recently-updated global database of surface seawater [DMS] (http://saga.pmel.noaa.gov/dms/) to examine the SRD relationship and comes to similar conclusions.

\section{Conclusions}

A challenge of Earth system science is to decouple the complex inter-relationships and feedbacks between the biosphere and climate. Vallina and Simó (2007) have demonstrated that a positive relationship may exist between the SRD and surface [DMS] over the seasonal DMS cycle using monthly averaged data. This is a necessary condition for the operation of a negative feedback (Charlson et al., 1987). The SRD methodology asserts that the interrelated seasonal cycles of MLD and surface insolation combine to produce high [DMS] when MLD are shallowest and summer insolation strongest. The SRD method is successful at combining these two relationships into one and provides a plausible bio-physical explanation for the strong correlations observed over the seasonal DMS cycle. The SRD methodology is troubled by the use of an estimated $I_{0}$ that does not realistically account for cloud cover, especially at this temporal resolution. This has implications for the CLAW hypothesis and the closure of any feedback loop which depends of the modulation of insolation by varying cloud albedo. The UVRD proposed here goes some way to addressing this issue producing a good correlation whilst utilising a cloud adjusted, surface irradiance product at a wavelength (UVA) with an implicated role in DMS(P) dynamics. Whether the SRD (or UVRD) illuminates causation beyond a simpler relationship with MLD or TOA-derived $I_{0}$ (i.e. a variable representing seasonality) at this resolution is questionable, at least within this AMT data. The MLD remains a useful shorthand to prediction without fully resolving the biological processes involved. However, it makes it harder to close the CLAW feedback loop. The suggested relationship between incident solar/ultraviolet radiation and sea surface DMS concentrations (modulated by MLD) makes it easier to close that feedback loop.

Acknowledgements. We thank Sergio Vallina for his help and advice on the SRD calculation and for supplying the climatological data. We thank Dominic Kniveton and Jay Harman for their help with the acquisition and compilation of the UV data. This work was supported by a Dean of Students Scholarship at the School of Environmental Sciences, University of East Anglia (Miles) and by the UK Natural Environment Research Council (NERC) as part of SOLAS Project Integration (Bell; NE/E001696/1) and the "Feedbacks QUEST" project (Lenton; NE/F001657/1). We thank the 2 anonymous reviewers and Rafel Simó for their considered and constructive comments.

Edited by: L. Bopp

\section{References}

Anderson, T. R., Spall, S. A., Yool, A., Cipollini, P., Challenor, P. G., and Fasham, M. J. R.: Global fields of sea surface dimethylsulfide predicted from chlorophyll, nutrients and light, J. Marine Syst., 30, 1-20, 2001.

Andreae, M. O. and Crutzen, P. J.: Atmospheric aerosols: Biogeochemical sources and role in atmospheric chemistry, Science, 276, 1052-1058, 1997.

Aranami, K. and Tsunogai, S.: Seasonal and regional comparison of oceanic and atmospheric dimethylsulfide in the northern North Pacific: Dilution effects on its concentration during winter, J. Geophys. Res.-Atmos., 109(15), D12303 10.1029/2003JD004288, 2004. 
Aumont, O., Belviso, S., and Monfray, P.: Dimethylsulfoniopropionate (DMSP) and dimethylsulfide (DMS) sea surface distributions simulated from a global three-dimensional ocean carbon cycle model, J. Geophys. Res.-Oceans, 107(C4), 3029, doi:10.1029/1999JC000111, 2002.

Ayers, G. P., Ivey, J. P., and Gillett, R. W.: Coherence between seasonal cycles of dimthyl sulphide, methansulphonate and sulphate in marine air, Nature, 349, 404-406, 1991.

Ayers, G. P. and Gillett, R. W.: DMS and its oxidation products in the remote marine atmosphere: implications for climate and atmospheric chemistry, J. Sea Res., 43, 275-286, 2000.

Bates, T. S., Lamb, B. K., Guenther, A., Dignon, J., and Stoiber, R. E.: Sulphur emissions to the atmosphere from natural sources, J. Atmos. Chem., 14, 315-337, 1992.

Bell, T. G., Malin, G., McKee, C. M., and Liss, P. S.: A comparison of dimethylsulphide (DMS) data from the Atlantic Meridional Transect (AMT) programme with proposed algorithms for global surface DMS concentrations, Deep-Sea Res. Pt. II, 53, 17201735, 2006.

Belviso, S., Bopp, L., Moulin, C., Orr, J. C., Anderson, T. R., Aumont, O., Chu, S., Elliott, S., Maltrud, M. E., and Simó, R.: Comparison of global climatological maps of sea surface dimethyl sulfide, Global Biogeochem. Cy., 18, GB3013, doi:10.1029/2003GB002193, 2004a.

Belviso, S., Moulin, C., Bopp, L., and Stefels, J.: Assessment of a global climatology of oceanic dimethylsulfide (DMS) concentrations based on SeaWiFS imagery (1998-2001), Can. J. Fish. Aquat. Sci., 61(5), 804-816, 2004b.

Belviso, S. and Caniaux, G.: A new assessment in North Atlantic waters of the relationship between DMS concentration and the upper mixed layer solar radiation dose, Global Biogeochem. Cy., 23, GB1014, doi:10.1029/2008GB003382, 2009.

Berresheim, H., Eisele, F. L., Tanner, D. J., McInnes, L. M., Ramseybell, D. C., and Covert, D. S.: Atmospheric sulpur chemistry and cloud condensation nuclei $(\mathrm{CCN})$ concentrations over the Northeastern pacific coast, J. Geophys. Res.-Atmos., 98, 1270112711, 1993.

Brimblecombe, P. and Shooter, D.: Photooxidation of dimethyl sulphide in aqueous solution, Mar. Chem., 19, 343-353, 1986.

Charlson, R. J., Lovelock, J. E., Andreae, M. O., and Warren, S. G.: Oceanic phytoplankton, atmospheric sulphur, cloud albedo and climate, Nature, 326, 655-661, 1987.

De Boyer Montégut, C. D., Madec, G., Fischer, A. S., Lazar, A., and Iudicone, D.: Mixed layer depth over the global ocean: An examination of profile data and a profile-based climatology, J. Geophys. Res.-Oceans, 109, C12003, doi:10.1029/2004JC002378, 2004.

Derevianko, G. J., Deutsch, C., and Hall, A.: On the relationship between ocean DMS and solar radiation, Geophys. Res. Lett, 36, L17606, doi:10.1029/2009GL039412, 2009.

Garcia-Pichel, F.: Solar ultraviolet and the evolutionary history of cyanobacteria, Origins Life Evol. B., 28, 321-347, 1998.

Häder, D. P., Kumar, H. D., Smith, R. C., and Worrest, R. C.: Aquatic ecosystems: effects of solar ultraviolet radiation and interactions with other climatic change factors, Photochem. Photobio. Sci., 2, 39-50, 2003.

Herman, J. R. and Celarier, E. A.: Earth surface reflectivity climatology at 340-380 nm from TOMS data, J. Geophys. Res.Atmos., 102, 28003-28011, 1997.
Kniveton, D. R., Todd, M. C., Sciare, J., and Mihalopoulos, N.: Variability of atmospheric dimethylsulphide over the southern Indian Ocean due to changes in ultraviolet radiation, Global Biogeochem. Cy., 17(4), 1096, doi:10.1029/2003GB002033, 2003.

Sciare, J., Baboukas, E., and Mihalopoulos, N.: Short-term variability of atmospheric DMS and its oxidation products at Amsterdam Island during summer time, J. Atmos. Chem., 39, 281-302, 2001.

Siegel, D. A. and Michaels, A. F.: Quantification of non-algal light attenuation in the Sargasso Sea: Implications for biogeochemistry and remote sensing, Deep-Sea Res. Pt. II, 43, 321-345, 1996.

Simó, R. and Pedros-Alio, C.: Role of vertical mixing in controlling the oceanic production of dimethyl sulphide, Nature, 402, 396399, 1999.

Simó, R.: Production of atmospheric sulfur by oceanic plankton: biogeochemical, ecological and evolutionary links, Trends Ecol. Evol., 16, 287-294, 2001.

Simó, R. and Dachs, J.: Global ocean emission of dimethylsulfide predicted from biogeophysical data, Global Biogeochem. Сy., 16(4), 1018, doi:10.1029/2001GB001829, 2002.

Slezak, D., Brugger, A., and Herndl, G. J.: Impact of solar radiation on the biological removal of dimethylsulfoniopropionate and dimethylsulfide in marine surface waters, Aquat. Microb. Ecol., 25, 87-97, 2001.

Steinke, M., Wolfe, G. V., and Kirst, G. O.: Partial characterisation of dimethylsulfoniopropionate (DMSP) lyase isozymes in 6 strains of Emiliania huxleyi, Mar. Ecol.-Prog. Ser., 175, 215225, 1998.

Steinke, M., Malin, G., Gibb, S. W., and Burkill, P. H.: Vertical and temporal variability of DMSP lyase activity in a coccolithophorid bloom in the northern North Sea, Deep-Sea Res. Pt. II, 49, 30013016, 2002.

Sunda, W., Kieber, D. J., Kiene, R. P., and Huntsman, S.: An antioxidant function for DMSP and DMS in marine algae, Nature, 418, 317-320, 2002.

Tedetti, M. and Sempere, R.: Penetration of ultraviolet radiation in the marine environment. A review, Photochem. Photobiol., 82, 389-397, 2006.

Toole, D. A., Kieber, D. J., Kiene, R. P., Siegel, D. A., and Nelson, N. B.: Photolysis and the dimethylsulfide (DMS) summer paradox in the Sargasso Sea, Limnol. Oceanogr., 48, 1088-1100, 2003.

Toole, D. A. and Siegel, D. A.: Light-driven cycling of dimethylsulfide (DMS) in the Sargasso Sea: Closing the loop, Geopys. Res. Lett., 31, L09308, doi:10.1029/2004GL019581, 2004.

Toole, D. A., Slezak, D., Kiene, R. P., Kieber, D. J., and Siegel, D. A.: Effects of solar radiation on dimethylsulfide cycling in the western Atlantic Ocean, Deep-Sea Res. Pt.-I, 53, 136-153, 2006.

Vallina, S. M. and Simó, R.: Strong relationship between DMS and the solar radiation dose over the global surface ocean, Science, 315, 506-508, 2007.

Vallina, S. M., Simó, R., Gassó, S., De Boyer-Montégut, C., del Río, E., Jurado, E., and Dachs, J.: Analysis of a potential "solar radiation dose-dimethylsulfide-cloud condensation nuclei" link from globally mapped seasonal correlations, Global Biogeochem. Cy., 21, GB2004, doi:10.1029/2006GB002787, 2007. 